\title{
An Update on the Genetics of Usher Syndrome
}

\author{
José M. Millán, ${ }^{1,2}$ Elena Aller, ${ }^{1,2}$ Teresa Jaijo, ${ }^{1,2}$ Fiona Blanco-Kelly, ${ }^{2,3}$ \\ Ascensión Gimenez-Pardo, ${ }^{2,3}$ and Carmen Ayuso ${ }^{2,3}$ \\ ${ }^{1}$ Unidad de Genética, Instituto de Investigación Sanitaria-La Fe, 46009 Valencia, Spain \\ ${ }^{2}$ Centro de Investigación Biomédica en Red de Enfermedades Raras (CIBERER), 46010 Valencia, Spain \\ ${ }^{3}$ Departamento de Genética Médica, Instituto de Investigación Sanitaria, Fundación Jiménez Díaz, Avenida Reyes Católicos 2, \\ 28040 Madrid, Spain \\ Correspondence should be addressed to Carmen Ayuso, cayuso@fjd.es
}

Received 29 June 2010; Accepted 15 November 2010

Academic Editor: Radha Ayyagari

Copyright ( 2011 José M. Millán et al. This is an open access article distributed under the Creative Commons Attribution License, which permits unrestricted use, distribution, and reproduction in any medium, provided the original work is properly cited.

Usher syndrome (USH) is an autosomal recessive disease characterized by hearing loss, retinitis pigmentosa (RP), and, in some cases, vestibular dysfunction. It is clinically and genetically heterogeneous and is the most common cause underlying deafness and blindness of genetic origin. Clinically, USH is divided into three types. Usher type I (USH1) is the most severe form and is characterized by severe to profound congenital deafness, vestibular areflexia, and prepubertal onset of progressive RP. Type II (USH2) displays moderate to severe hearing loss, absence of vestibular dysfunction, and later onset of retinal degeneration. Type III (USH3) shows progressive postlingual hearing loss, variable onset of RP, and variable vestibular response. To date, five USH1 genes have been identified: MYO7A (USH1B), CDH23 (USH1D), PCDH15 (USH1F), USH1C(USH1C), and USH1G(USH1G). Three genes are involved in USH2, namely, USH2A (USH2A), GPR98 (USH2C), and DFNB31 (USH2D). USH3 is rare except in certain populations, and the gene responsible for this type is $U S H 3 A$.

\section{Introduction}

Usher syndrome (USH) was first described by von Graefe in 1858 and is characterized by the association of sensorineural hearing loss, retinitis pigmentosa (RP), and, in some cases, vestibular dysfunction. Its heritability was established by Charles Usher, a British ophthalmologist [1]. The syndrome is inherited in an autosomal recessive pattern. The syndrome is the most frequent cause of deaf-blindness, accounting for more than $50 \%$ of individuals who are both deaf and blind $[2,3]$, about $18 \%$ of RP cases [4], and $5 \%$ of all cases of congenital deafness [5]. Its range of prevalence is 3.2$6.2 / 100,000$ depending on the study $[2,4,6-8]$.

Usher patients present progressive photoreceptor degeneration in the retina called retinitis pigmentosa, which leads to a loss of peripheral vision. This degeneration is predominantly attributable to rod dysfunction, although cones usually degenerate later in the course of the disease.
Clinical symptoms may vary and include night blindness (nyctalopia) with elevated dark adaptation thresholds, abnormal electroretinogram responses, visual field constriction, abnormal retinal pigmentation including peripheral bone spicules, arterial narrowing, and optic-nerve pallor, and predisposition to myopia and posterior subcapsular cataracts [9].

The human inner ear consists of the cochlea, a snailshaped organ which mediates sound transduction, and the vestibular labyrinth, which detects gravitational force and angular and linear accelerations. Both structures have specialized hair cells which convert mechanical stimuli into variations of intracellular potential, thus transmitting afferent nerve signals toward the brain. On the apical surface of these cells there is a mechanosensitive organelle, the hair bundle, which consists of precisely organized actinfilled projections known as stereocilia. In Usher syndrome patients, alteration in the morphogenesis and stability of 
stereocilia results in sensorineural hearing loss and may also cause balance defects [10].

The majority of patients with Usher syndrome usually fall into one of three clinical categories [11]. Of these, Usher syndrome type I (USH1) is the most severe form, consisting of profound hearing loss and vestibular dysfunction from birth. Moreover, onset of RP occurs earlier in USH1 than in Usher syndrome type II (USH2), which produces less severe congenital hearing loss and does not impair normal vestibular function. In most populations, USH1 accounts for approximately one-third of USH patients whereas twothirds are classified as USH2. Usher syndrome type III (USH3) is a less common form except in such populations as Finns and Ashkenazi Jews. In this USH3 type, hearing loss is progressive and leads to variable vestibular dysfunction and onset of RP. Table 1 outlines the clinical characteristics of each type. Some cases are not easily classifiable under the aforementioned categories and could be categorized as atypical USH syndrome [12].

All subtypes are genetically heterogeneous and 12 loci have been described, namely, USH1B-H, USH2A, C-D, and USH3A-B (hereditary hearing loss homepage: http://hereditaryhearingloss.org). Nine genes have been identified through the discovery of a mouse homolog or by positional cloning. There are five USH1 genes that codify known products: myosin VIIA (MYO7A), the two cell-cell adhesion cadherin proteins cadherin-23 $(\mathrm{CDH} 23)$ and protocadherin-15 (PCDH15), and the scaffold proteins harmonin (USH1C) and SANS (USH1G). The three identified USH2 genes are $U S H 2 A$, which codes for the transmembrane protein usherin (USH2A); the G-protein-coupled 7-transmembrane receptor VLGR1 (GPR98), and whirlin (DFNB31), another scaffolding protein. The USH3A gene encodes clarin-1, which exhibits 4 transmembrane domains. Mutations in any one of these genes cause primary defects of the sensory cells in the inner ear and the photoreceptor cells of the retina, both being the source of the clinical symptoms of USH.

Many of these genes can also cause either nonsyndromic hearing loss (NSHL) or isolated RP. In fact, MYO7A causes DFNB2/DFNA11 [13, 14]; USH1C also causes DFNB18 $[15,16]$; $C D H 23$ causes DFNB12 [17, 18]; PCDH15 causes DFNB23 [19]; mutations in DFNB31 also lead to DFNB31 $[20,21]$. Moreover, some mutations in the USH $2 A$ gene cause isolated RP [22]. Table 2 shows the genetic classification of Usher syndrome, the implicated loci and responsible genes, as well as the involvement of USH in nonsyndromic hearing loss and RP.

\section{Usher Syndrome Type I}

2.1. Clinical Features. Usher syndrome type I is the most severe form. USH1 patients suffer from severe to profound congenital and bilateral sensorineural hearing loss. These individuals are either born completely deaf or experience hearing impairment within the first year of life and usually do not develop speech.

Constant vestibular dysfunction is present from birth; children manifest a delay in motor development and begin sitting independently and walking later than usual.
Onset of retinitis pigmentosa occurs during childhood, resulting in a progressively constricted visual field and impaired visual acuity which rapidly proceeds to blindness. Anomalies of light-evoked electrical response of the retina can be detected by electroretinography at 2-3 years of age, which allows for early diagnosis of the disease.

2.2. Genetic Findings. Seven loci (USH1B-USH1H) have been mapped and five causative Usher genes have been cloned: MYO7A, USH1C, CDH23, PCDH15, and USH1G, which are known to be implicated in USH1B, USH1C, USH1D, USH1F, and USH1G, respectively.

Several studies have investigated the MYO7A gene, identifying a wide range of mutations (reviewed in [23]). These reports reveal that the myosin VIIA gene bears the main responsibility for Usher type I. Its implication ranges from $29 \%$ to $\sim 50 \%$ in different populations [24-27]. CDH23 is probably the second most common mutated gene underlying USH1. Its prevalence accounts for $19 \%-35 \%$ of USH1 families $[23,25,26,28]$. The next most frequent is $P C D H 15$, reportedly involved in about $11 \%-19 \%$ of USH1 cases with and a significant proportion of cases due to large genomic rearrangements $[25,26,29,30]$. The remaining genes show a minor implication in the disorder, with the USH1C gene accounting for $6 \%-7 \%[25,26]$ and the USH $1 G$ for $7 \%$ as seen in USH1 populations from the United States and the United Kingdom [31]. However, in cohorts of USH1 patients from France and Spain screened for the USH1G gene, no pathological mutations have been identified [26, 32]. There are some exceptions to this distribution due to mutation founder effects in specific populations. As an example, the mutation c.216G $>$ A in USH1C found in French Canadians of Acadian origin accounts for virtually all USH1 cases in this population [33] but has not been found in other populations; or the c.733C > T (p.R254X) in the PCDH15 [34] gene, which is present in up to $58 \%$ of USH1 families of Ashkenazi origin.

\section{Usher Syndrome Type II}

3.1. Clinical Features. Firstly, RP symptoms manifest later in USH2 patients than in their USH1 counterparts, for whom onset occurs during or after puberty.

The degree of hearing impairment in patients diagnosed with USH2 increases from moderate in low frequencies to severe in high frequencies, tending to remain stable. Hearing loss is congenital but may be detected at later stages when it hinders communication.

Vestibular function in Usher type II patients is normal.

3.2. Genetic Findings. To date, three loci (USH2A, USH2C$2 D$ ) have been proposed as being responsible for USH2, and three causative genes have been identified: USH2A (USH2A), GPR98 (USH2C), and DFNB31 (USH2D).

Mutational screenings performed on the long isoform of the USH2A gene exons have shown that USH2A is involved in $55 \%-90 \%$ of USH 2 cases [35-39]. Of the high number of mutations detected in this huge gene, the c.2299delG mutation is the most prevalent and accounts for $45 \%-15 \%$ 
TABLE 1: Clinical features of Usher syndrome types.

\begin{tabular}{lccc}
\hline & USH1 & USH2 & USH3 \\
\hline \multirow{2}{*}{ Hearing loss } & Severe to profound & Moderate to severe & Moderate to severe \\
& Congenital & Congenital & Progressive \\
Vestibular function & Stable & Normal & Variable \\
RP onset & Usually prepubertal & Around pubertyor postpubertal & Around puberty or postpubertal \\
Language & Unintelligible & Intelligible & Intelligible \\
\hline
\end{tabular}

TABLE 2: Genetic classification of Usher syndrome.

\begin{tabular}{lccl}
\hline Locus & Location & Gene/protein & Function \\
\hline USH1B/DFNB2/DFNA1 & $11 \mathrm{q} 13.5$ & MYO7A/myosin VIIA & IE and R: transport \\
USH1C/DFNB18 & $11 \mathrm{p} 15.1$ & USH1C/harmonin & IE and R: scaffolding \\
USH1D/DFNB12 & $10 \mathrm{q} 22.1$ & $C D H 23 /$ cadherin 23 & IE: tip link formation; R: periciliary maintenance \\
USH1E & $21 \mathrm{q} 21$ & $-/-$ & Unknown \\
USH1F/DFNB23 & $10 \mathrm{q} 21.1$ & PCDH15/protocadherin 15 & IE: tip link formation; R: periciliary maintenance \\
USH1G & $17 \mathrm{q} 25.1$ & USH1G/SANS & IE and R: scaffolding and protein trafficking \\
USH1H & $15 \mathrm{q} 22-23$ & $-/-$ & Unknown \\
USH2A/RP & $1 \mathrm{q} 41$ & USH2A/usherin & $\begin{array}{l}\text { IE: ankle links formation and cochlear development; R: } \\
\text { periciliary maintenance }\end{array}$ \\
USH2C & $5 \mathrm{q} 14.3$ & GPR98/VLGR1 & $\begin{array}{l}\text { IE: ankle links formation Cochlear development; R: periciliary } \\
\text { maintenance }\end{array}$ \\
USH2D/DFNB31 & $9 \mathrm{q} 32-34$ & DFNB31/whirlin & IE: scaffolding and cochlear development; R: scaffolding \\
USH3A & $3 \mathrm{q} 25.1$ & USH3A/clarin-1 & IE and R: probable role in synapsis transport* \\
USH3B & $20 \mathrm{q}$ & $-/-$ & Unknown
\end{tabular}

USH: usher syndrome; DFNB: autosomal recessive deafness; DFNA: autosomal dominant deafness; RP: retinitis pigmentosa; IE: inner ear; R: retina.

* A role in the retinal and inner ear synapses as been proposed for all the USH proteins. This remains to be elucidated.

of all mutated alleles [37, 40]. The c.2299delG mutation appears to be an ancestral mutation of European origin which spread from Europe to other regions of the world during colonization, and it shows a particular distribution decreasing in frequency from Northern to Southern Europe [40]. Again, a founder effect has been identified for the c.4338_4339delCT deletion (p.C1447QfsX29) in the USH2A gene which accounts for $55.6 \%$ of the USH2 alleles among Quebec French-Canadians [41].

To date, few mutation screenings have been published on GPR98, although based upon the results available, mutations in GPR98 do not seem to be responsible for a large proportion of USH 2 cases, approximately $3 \%-5.6 \%[39,42]$.

Ebermann et al. found two DFNB31 mutations in a German family suffering from USH2 [21]. Later, in a transnational study, Aller et al. failed to find any pathological mutation in a series of 195 USH patients [43]. DFNB31 mutations appear to be a rare cause of recessive hearing loss and Usher syndrome.

\section{Usher Syndrome Type III}

4.1. Clinical Features. The onset of RP symptoms (nyctalopia, progressive constriction of visual field, and reduction of central visual acuity) is variable though usually occurs by the second decade of life.
Sensorineural hearing loss is postlingual and progressive and can appear between the first and third decade of life. In its initial stages, the degree of hearing impairment is similar to that seen in USH2, with major impairment seen in high frequencies. The progression rate is variable but, in most cases, hearing loss becomes profound. Nevertheless, hearing levels during the first stages of development are good enough to permit well-developed speech. Thus, successive audiometric examinations are needed in USH3 patients in order to obtain an accurate clinical diagnosis. The vestibular responses are also variable, with $50 \%$ of cases experiencing impairment.

4.2. Genetic Findings. Although the USH3A gene was initially described as being responsible for USH3 cases, recent studies have demonstrated that mutations in USH3A can also produce clinical forms of Usher that are similar to USH1 and USH2 $[44,45]$. Usher syndrome type III is the least common clinical type of the syndrome in the general population. However, in some populations like the Finns or the Ashkenazi Jews, the syndrome accounts for over $40 \%$ of USH cases due to the mutation founder effect of c.300T>C (p.Y176X; known as the Finn mayor mutation) and c. $143 \mathrm{~T}>\mathrm{C}$ (p.N48K), respectively, [46, 47].

The existence of a second locus for this clinical type (USH3B) was suggested by Chaïb et al. in 1997, although these findings have yet to be confirmed in [48]. 


\section{The Usher Interactome}

The proteins encoded by the identified USH genes belong to different protein classes. Myosin VIIA (USH1B) is an actin-based motor protein; harmonin (USH1C), SANS (USH1G), and whirlin (USH2D) are scaffolding proteins [20, 49, 50]; cadherin 23 (USH1D) and protocadherin $15(U S H 1 F)$ are cell-adhesion molecules [15, 51]; usherin (USH2A) and VLGR1 (USH2C) are transmembrane proteins with very large extracellular domains $[42,52]$. Finally, clarin1 (USH3A) is a protein with four transmembrane domains [53]. All these proteins have one or several protein-protein interaction domains.

USH1 and USH2 proteins are integrated in a protein network known as Usher "interactome."

The central core of the interactome is formed by the PDZ domain containing the homologues harmonin and whirlin and the microtubule-associated protein SANS, with the remaining USH proteins attached to this core (Figure 1).

Many of the USH proteins also interact with other proteins that are present in the inner ear and retina. These additional interacting proteins may cause Usher syndrome, nonsyndromic hearing loss, or retinal dystrophies.

Recently, one of these proteins, the protein encoded by the PDZD7 gene, has been shown to be involved in the pathogenesis of Usher syndrome. Mutations in PDZD7 act as negative modifiers of the phenotype [54].

The localization of the Usher proteins in the hair cells of the organ of Corti and in the photoreceptor cells suggests that they play an important role in the neurosensorial function of both the inner ear and the retina.

5.1. The USH Interactome in the Inner Ear. The main sites of colocalization of Usher proteins are the stereocilia and the synaptic regions of hair cells.

Usher proteins are essential for the correct development and cohesion of the hair bundle of hair cells in the cochlea and vestibular organ (reviewed in [56-58]).

In murine models, hair cells in the developing inner ear, known as stereocilia, maintain their cohesion by interstereocilia fibrous links and links with the kinocilium. There are several types of links depending on the stage of hair-cell development. In the mouse, transient lateral links appear at very early stages of stereocilia formation, but while other links appear at the base of stereocilia (ankle links), these lateral links diminish progressively throughout development. Later, ankle links diminish, and tip and horizontal links appear and are preserved in adulthood [10].

The large extracellular domains of the cell adhesion proteins cadherin-23 and protocadherin-15 and the transmembrane proteins usherin and VLGR1 are part of these links. The proteins are anchored to the intracellular scaffolding proteins harmonin and/or whirlin, which connect, via myosinVIIa and possibly other interactome proteins, to the actin core of the stereocilia $[55,56,59,60]$.

The role of the different proteins in the links probably depends on the spatiotemporal stage of the links. It has been proposed that protocadherin-15 and cadherin-23 in the tip link play an essential role in triggering the mechanotransduction cascade [61]. McGee et al. proposed that usherin and VLGR1 are expressed in the transient ankle links [62].

Usher proteins also take part in the transport of vesicles from the cuticular plate to the growing apical tip of stereocilia [56].

Besides this, the presence of many of these proteins in the synaptic regions of inner and/or outer hair cells suggests that the Usher interactome might play a role in the neurotransmission of the mechanotransduction signal $[58,60,63]$.

5.2. The USH Interactome in the Retina. There is evidence that myosin VIIa plays a role in the transport of opsin from the inner segment to the outer segment of the photoreceptors through the connecting cilium. Such evidence appears in studies in shaker-1, the mouse model defective for myosin VIIA, since shaker-1 accumulates opsin in the ciliary plasma membrane of photoreceptor cells $[64,65]$.

Further studies have proven that both USH1 and USH2 proteins interact in the ciliary/periciliary region of cone and rod photoreceptors. The proteins usherin, VLGR1b, and SANS are associated with the periciliary ridge complex, which is thought to be the docking side for cargo loaded postGolgi vesicles [66]. In mammals, this specialized domain extends over the plasma membrane of the proximal part of the calycal process, which is connected via extracellular fibrous links to the plasma membrane of the connecting cilium. In the extracellular space between the membranes of the inner segment and the connecting cilium, the extracellular domains of usherin and VLGR1b may be part of these links, perhaps by means of homomeric, heteromeric, or both interactions together. Furthermore, the short intracellular domains of usherin and VLGR1b anchor to whirlin in the cytoplasm. Finally, whirlin would link to SANS and myosin VIIa, which directly interact with the cytoskeleton microtubules and F-actin filaments [67]. Cadherin-23, vezatin, and maybe other partners of the multiprotein complex that bind myosin VIIa may serve as anchors for this molecular motor at the periciliary membrane (reviewed in $[57,68]$ ). Thus, the Usher protein network should provide mechanical support to the membrane junction between the inner segment and the connecting cilium, participating in the control of vesicle docking and cargo handover in the periciliary ridge.

Usher proteins also localize in the photoreceptor synapse, as they do in the hair cells in the organ of Corti, where they could form a complex involved in the trafficking of the synaptic vesicles [57]. However, some researchers do not support this idea since there are no mouse models with photoreceptor synaptic dysfunction [69].

In the retinal pigment epithelium (RPE) the absence of myosin VIIa causes a significant decrease in phagocytosis of outer segment disks by the pigment epithelial cells [70], suggesting a role for myosin VIIa in the shedding and phagocytosis of the distal outer segment disks by the RPE. A role involving the intracellular transport of melanosomes in the RPE cells has also been proposed for myosin VIIa [56]. The same authors suggested that protocadherin-15, together with cadherin-23 or other cadherins, could ensure 


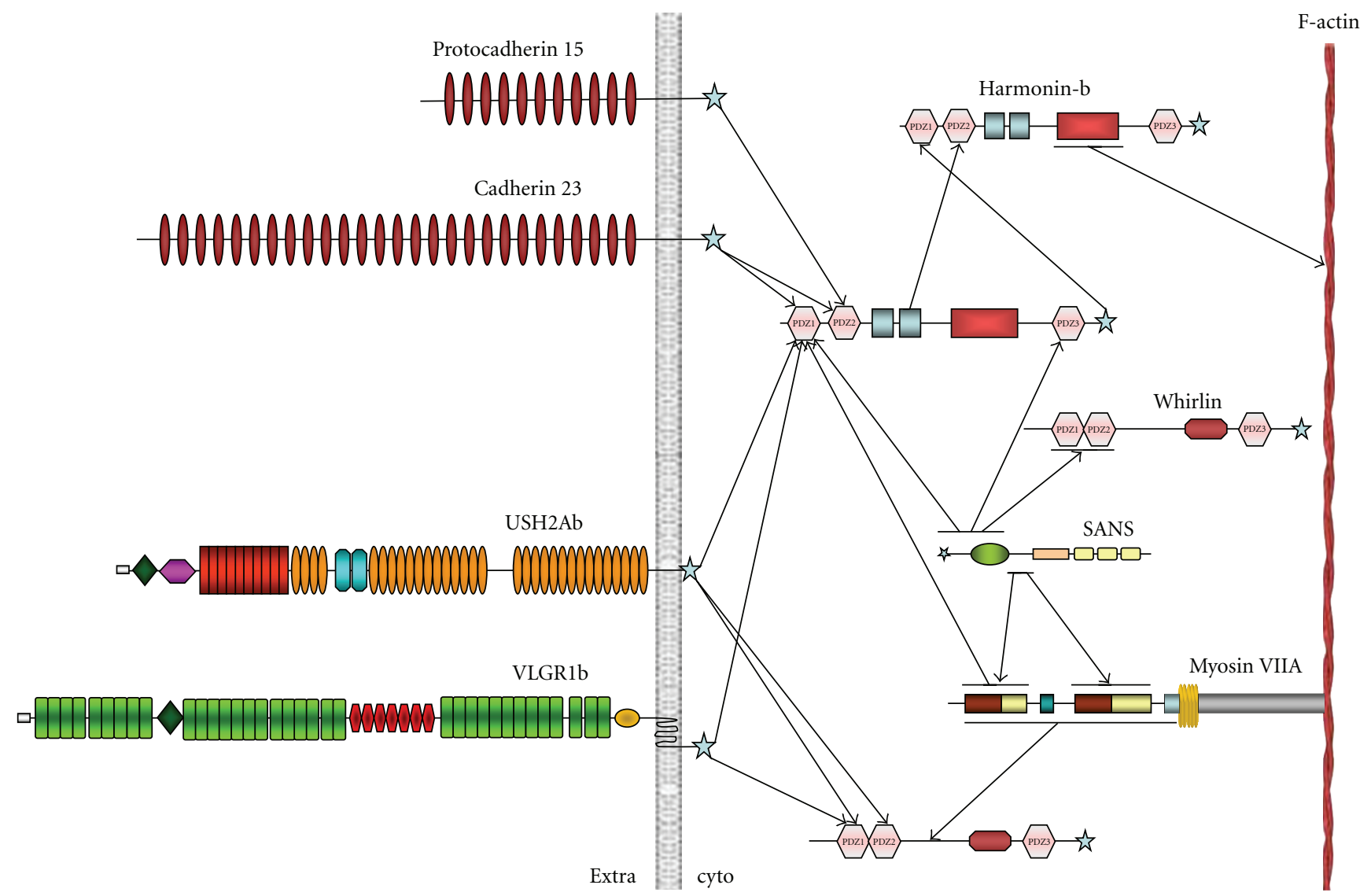

FIGURE 1: Schematic diagram illustrating the deciphered interactions within the USH protein network interactome adapted from van Wijk et al. [55].

proper alignment of outer segment disks of photoreceptors and apical microvilli of RPE cells through interactions with harmonin. However, none of the USH2 proteins have been shown to be present in the RPE.

Most of the USH genes are responsible not only for Usher syndrome but also for nonsyndromic hearing loss. To date, however, only one gene (USH2A) is known to be responsible for isolated RP, which suggests that usherin plays a main role for the photoreceptor or that the rest of the Usher proteins are not essential in the photoreceptor function.

\section{Conclusion}

6.1. Diagnosis. Usher syndrome is a clinically and genetically heterogeneous disorder which is important from a public health viewpoint because of the social isolation which Usher patients must endure. The first step towards correct diagnosis is proper differential diagnosis of the syndrome.

Initially, USH manifests as a sensorineural hearing impairment, sometimes with vestibular dysfunction, with RO onset occurring later in life. Several syndromes may exhibit clinical signs which are similar to USH. Differential diagnosis should take into account the presence of endocrine abnormalities such insulin resistance, type 2 diabetes, hypertriglyceridemia, hepatic dysfunction, and/or renal failure, all of them would indicate Alström syndrome or the presence of obesity, mental retardation or cognitive impairment, and postaxial polydactly and hypogenitalism, which may be indicators of a Bardet-Biedl syndrome (BBS). If a family history of X-linked inheritance is observed, or if signs of dystonia or ataxia are detected, Mohr-Tranebjaerg syndrome should be suspected.

Genetic tests could be a very powerful tool in differential diagnosis of USH patients. However, there are many factors that make the genetic study of this disease a complicated difficult one. As explained in this paper, the genes identified to date do not explain all the USH cases (this is true for BBS and Alström syndromes as well), and the variable nature of the proteins involved in USH and the complexity of the USH interactome make identifying novel genes a difficult task. This is due to genetic and allelic heterogeneity, which contribute to the low rate of mutation detection, together with the possible presence of large deletions, mutations in noncoding regions, or isoforms in low concentration only present in the affected tissues. Moreover, other complex inheritance forms could modify the phenotype and its expression, as recently shown by Ebermann et al. [54]. All of these factors make the use of traditional techniques for mutation detection difficult.

Application of new technologies based on DNA chips could solve this problem; in fact, the recent creation of a specific microchip for this disease $[71,72]$ permits the 
identification of mutations in $30 \%-50 \%$ of the affected patients and requires only a very small DNA sample, and the technique is both cheap and fast $[71-73,72]$. Advances in massive sequencing technologies will certainly change the approaches to molecular diagnosis of Usher syndrome.

Gene characterization and mutation screening will unravel the functional aspects and allow a phenotypegenotype correlation to be established.

6.2. Therapy. Currently, there is no treatment available for Usher syndrome. The hearing-loss problem can be solved by the use of hearing aids and cochlear implantation, but the retinal problem remains unsolved. Therapeutic strategies to treat retinal degeneration target the specific genetic disorder (gene therapy), slowing or stopping photoreceptor degeneration or apoptosis (e.g., growth factors or calcium blocker applications, vitamin supplementation, and endogenous cone viability factors) or even the replacement of lost cells (e.g, transplantation, use of stem or precursor cells) (reviewed in [73]). However, before these strategies can be applied to humans, animal models, pre clinical studies, and appropriately designed human clinical trials are needed to test different treatments and provide information on their safety and efficacy.

\section{Acknowledgments}

The authors acknowledge the patient associations (ONCE, FAARPEE, Fundación Retina España, and ASOCIDE). CIBERER is an initiative of the Instituto de Salud Carlos III, Ministry of Science and Innovation. This work was supported by the projects PI07/0557 and PI08/90311, PS09/00459, and PI09/900047. They would also like to thank the work of Marta Cortón, María J. Aparisi, and Gema García-García.

\section{References}

[1] C. H. Usher, "Bowman's lecture: on a few hereditary eye affections," Transactions of the Ophthalmological Societies of the United Kingdo, vol. 55, pp. 164-245, 1935.

[2] M. Vernon, "Sociological and psychological factors associated with hearing loss," Journal of Speech and Hearing Research, vol. 12, no. 3, pp. 541-563, 1969.

[3] H. M. Fortnum, A. Q. Summerfield, D. H. Marshall, A. C. Davis, and J. M. Bamford, "Prevalence of permanent childhood hearing impairment in the United Kingdom and implications for universal neonatal hearing screening: questionnaire based ascertainment study," British Medical Journal, vol. 323, no. 7312, pp. 536-539, 2001.

[4] J. A. Boughman, M. Vernon, and K. A. Shaver, "Usher syndrome: definition and estimate of prevalence from two high-risk populations," Journal of Chronic Diseases, vol. 36, no. 8, pp. 595-603, 1983.

[5] M. L. Marazita, L. M. Ploughman, B. Rawlings, E. Remington, K. S. Arnos, and W. E. Nance, "Genetic epidemiological studies of early-onset deafness in the U.S. school-age population," American Journal of Medical Genetics, vol. 46, no. 5, pp. 486491, 1993.
[6] C. I. Hope, "Usher syndrome in the city of Birminghamprevalence and clinical classification," British Journal of Ophthalmology, vol. 81, no. 1, pp. 46-53, 1997.

[7] T. Rosenberg, M. Haim, A. M. Hauch, and A. Parving, "The prevalence of Usher syndrome and other retinal dystrophyhearing impairment associations," Clinical Genetics, vol. 51, no. 5, pp. 314-321, 1997.

[8] C. Espinos, J. M. Millan, M. Beneyto et al., "Epidemiology of Usher syndrome in Valencia and Spain," Community Genet, vol. 1, pp. 223-228, 1998.

[9] M. Kalloniatis and E. L. Fletcher, "Retinitis pigmentosa: understanding the clinical presentation, mechanisms and treatment options," Clinical and Experimental Optometry, vol. 87, no. 2, pp. 65-80, 2004.

[10] G. I. Frolenkov, I. A. Belyantseva, T. B. Friedman, and A. J. Griffith, "Genetic insights into the morphogenesis of inner ear hair cells," Nature Reviews Genetics, vol. 5, no. 7, pp. 489-498, 2004.

[11] S. L. H. Davenport and G. S. Omenn, "The heterogeneity of Usher's syndrome," in Proceedings of the 5th International Conference of Birth Defects, 1977, abstract 215.

[12] C. R. Otterstedde, U. Spandau, A. Blankenagel, W. J. Kimberling, and C. Reisser, "A new clinical classification for Usher's syndrome based on a new subtype of Usher's syndrome type I," Laryngoscope, vol. 111, no. 1, pp. 84-86, 2001.

[13] X. Z. Liu, J. Walsh, P. Mburu et al., "Mutations in the myosin VIIA gene cause non-syndromic recessive deafness," Nature Genetics, vol. 16, no. 2, pp. 188-190, 1997.

[14] X. Z. Liu, J. Walsh, Y. Tamagawa et al., "Autosomal dominant non-syndromic deafness caused by a mutation in the myosin VIIA gene," Nature Genetics, vol. 17, no. 3, pp. 268-269, 1997.

[15] Z. M. Ahmed, T. N. Smith, S. Riazuddin et al., "Nonsyndromic recessive deafness DFNB18 and usher syndrome type IC are allelic mutations of USHIC," Human Genetics, vol. 110, no. 6, pp. 527-531, 2002.

[16] X. M. Ouyang, X. J. Xia, E. Verpy et al., "Mutations in the alternatively spliced exons of USH1C cause non-syndromic recessive deafness," Human Genetics, vol. 111, no. 1, pp. 2630, 2002.

[17] L. M. Astuto, J. M. Bork, M. D. Weston et al., "CDH23 mutation and phenotype heterogeneity: a profile of 107 diverse families with Usher syndrome and nonsyndromic deafness," American Journal of Human Genetics, vol. 71, no. 2, pp. 262-275, 2002.

[18] J. M. Bork, L. M. Peters, S. Riazuddin et al., "Usher syndrome $1 \mathrm{D}$ and nonsyndromic autosomal recessive deafness DFNB12 are caused by allelic mutations of the novel cadherin-like gene CDH23," American Journal of Human Genetics, vol. 68, no. 1, pp. 26-37, 2001.

[19] Z. M. Ahmed, S. Riazuddin, S. L. Bernstein et al., "Mutations of the protocadherin gene PCDH15 cause usher syndrome type 1F," American Journal of Human Genetics, vol. 69, no. 1, pp. 25-34, 2001.

[20] P. Mburu, M. Mustapha, A. Varela et al., "Defects in whirlin, a PDZ domain molecule involved in stereocilia elongation, cause deafness in the whirler mouse and families with DFNB31," Nature Genetics, vol. 34, no. 4, pp. 421-428, 2003.

[21] I. Ebermann, H. P. N. Scholl, P. Charbel Issa et al., "A novel gene for Usher syndrome type 2: mutations in the long isoform of whirlin are associated with retinitis pigmentosa and sensorineural hearing loss," Human Genetics, vol. 121, no. 2, pp. 203-211, 2007.

[22] C. Rivolta, E. A. Sweklo, E. L. Berson, and T. P. Dryja, "Missense mutation in the USH2A gene: association with 
recessive retinitis pigmentosa without hearing loss," American Journal of Human Genetics, vol. 66, no. 6, pp. 1975-1978, 2000.

[23] Z. M. Ahmed, S. Riazuddin, S. Riazuddin, and E. R. Wilcox, "The molecular genetics of Usher syndrome," Clinical Genetics, vol. 63, no. 6, pp. 431-444, 2003.

[24] A. K. Bharadwaj, J. P. Kasztejna, S. Huq, E. L. Berson, and T. P. Dryja, "Evaluation of the myosin VIIA gene and visual function in patients with usher syndrome type I," Experimental Eye Research, vol. 71, no. 2, pp. 173-181, 2000.

[25] X. M. Ouyang, D. Yan, LI. L. Du et al., "Characterization of Usher syndrome type I gene mutations in an Usher syndrome patient population," Human Genetics, vol. 116, no. 4, pp. 292299, 2005.

[26] A. F. Roux, V. Fougère, S. Le Guédard et al., "Survey of the frequency of USH1 gene mutations in a cohort of Usher patients shows the importance of cadherin 23 and protocadherin 15 genes and establishes a detection rate of above 90\%," Journal of Medical Genetics, vol. 43, no. 9, pp. 763-768, 2006.

[27] T. Jaijo, E. Aller, S. Oltra et al., "Mutation profile of the MYO7A gene in Spanish patients with Usher syndrome type I," Human Mutation, vol. 27, no. 3, pp. 290-291, 2006.

[28] A. Oshima, T. Jaijo, E. Aller et al., "Mutation profile of the CDH23 gene in 56 probands with Usher syndrome type I," Human Mutation, vol. 29, no. 6, pp. E37-E46, 2008.

[29] S. Le Guédard, V. Faugère, S. Malcolm, M. Claustres, and A. F. Roux, "Large genomic rearrangements within the PCDH15 gene are a significant cause of USH1F syndrome," Molecular Vision, vol. 13, pp. 102-107, 2007.

[30] E. Aller, T. Jaijo, G. García-García et al., "Identification of large rearrangements of the PCDH15 gene by combined MLPA and oligonucleotide CGH-array: large duplications can be responsible for Usher syndrome," Investigative Ophthalmology \& Visual Science, vol. 51, pp. 5480-5485, 2010.

[31] X. M. Ouyang, J. F. Hejtmancik, S. G. Jacobson et al., "USH1C: a rare cause of USH1 in a non-Acadian population and a founder effect of the Acadian allele," Clinical Genetics, vol. 63, no. 2, pp. 150-153, 2003.

[32] E. Aller, T. Jaijo, M. Beneyto et al., "Screening of the USH1G gene among Spanish patients with usher syndrome. Lack of mutations and evidence of a minor role in the pathogenesis of the syndrome," Ophthalmic Genetics, vol. 28, no. 3, pp. 151$155,2007$.

[33] I. Ebermann, I. Lopez, M. Bitner-Glindzicz, C. Brown, R. K. Koenekoop, and H. J. Bolz, "Deafblindness in French Canadians from Quebec: a predominant founder mutation in the USH1C gene provides the first genetic link with the Acadian population," Genome Biology, vol. 8, no. 4, article R47, 2007.

[34] T. Ben-Yosef, S. L. Ness, A. C. Madeo et al., "A mutation of PCDH15 among Ashkenazi Jews with the type 1 Usher syndrome," The New England Journal of Medicine, vol. 348, no. 17, pp. 1664-1670, 2003.

[35] E. Aller, T. Jaijo, M. Beneyto et al., "Identification of 14 novel mutations in the long isoform of USH2A in Spanish patients with Usher syndrome type II," Journal of Medical Genetics, vol. 43, no. 11, article e55, 2006.

[36] D. Baux, L. Larrieu, C. Blanchet et al., "Molecular and in silico analyses of the full-length isoform of usherin identify new pathogenic alleles in usher type II patients," Human Mutation, vol. 28, no. 8, pp. 781-789, 2007.

[37] B. Dreyer, V. Brox, L. Tranebjaerg et al., "Spectrum of USH2A mutations in Scandinavian patients with Usher syndrome type II," Human Mutation, vol. 29, no. 3, p. 451, 2008.
[38] T. L. McGee, B. J. Seyedahmadi, M. O. Sweeney, T. P. Dryja, and E. L. Berson, "Novel mutations in the long isoform of the USH2A gene in patients with Usher syndrome type II or nonsyndromic retinitis pigmentosa," Journal of Medical Genetics, vol. 47, no. 7, pp. 499-506, 2010.

[39] T. Besnard, C. Vaché, and L. Larrieu, "Implication of GPR98 in Usher syndrome type 2," in International Symposium on Usher Syndrome and Related Diseases, Valencia, Spain, May 2010.

[40] E. Aller, L. Larrieu, T. Jaijo et al., "The USH2A c.2299delG mutation: dating its common origin in a Southern European population," European Journal of Human Genetics, vol. 18, no. 7, pp. 788-793, 2010.

[41] I. Ebermann, R. K. Koenekoop, I. Lopez, L. Bou-Khzam, R. Pigeon, and H. J. Bolz, "An USH2A founder mutation is the major cause of Usher syndrome type 2 in Canadians of French origin and confirms common roots of Quebecois and Acadians," European Journal of Human Genetics, vol. 17, no. 1, pp. 80-84, 2009.

[42] M. D. Weston, M. W. J. Luijendijk, K. D. Humphrey, C. Möller, and W. J. Kimberling, "Mutations in the VLGR1 gene implicate G-protein signaling in the pathogenesis of Usher syndrome type II," American Journal of Human Genetics, vol. 74, no. 2, pp. 357-366, 2004.

[43] E. Aller, T. Jaijo, E. van Wijk et al., "Sequence variants of the DFNB31 gene among Usher syndrome patients of diverse origin," Molecular vision, vol. 16, pp. 495-500, 2010.

[44] R. J. E. Pennings, A. F. Deutman, R. R. Fields, W. J. Kimberling, P. L. M. Huygen, and C. W. R. J. Cremers, "Usher syndrome type III can mimic other types of Usher syndrome," Annals of Otology, Rhinology and Laryngology, vol. 112, no. 6, pp. 525530, 2003.

[45] E. Aller, T. Jaijo, S. Oltra et al., "Mutation screening of USH3 gene (clarin-1) in Spanish patients with Usher syndrome: low prevalence and phenotypic variability," Clinical Genetics, vol. 66, no. 6, pp. 525-529, 2004.

[46] T. Joensuu, R. Hämäläinen, B. Yuan et al., "Mutations in a novel gene with transmembrane domains underlie usher syndrome type 3," American Journal of Human Genetics, vol. 69, no. 4, pp. 673-684, 2001.

[47] S. L. Ness, T. Ben-Yosef, A. Bar-Lev et al., "Genetic homogeneity and phenotypic variability among Ashkenazi Jews with Usher syndrome type III," Journal of Medical Genetics, vol. 40, no. 10, pp. 767-772, 2003.

[48] H. Chaïb, J. Kaplan, S. Gerber et al., "A newly identified locus for Usher syndrome type I, USH1E, maps to chromosome 21q21," Human Molecular Genetics, vol. 6, no. 1, pp. 27-31, 1997.

[49] E. Verpy, M. Leibovici, I. Zwaenepoel et al., "A defect in harmonin, a PDZ domain-containing protein expressed in the inner ear sensory hair cells, underlies Usher syndrome type 1C," Nature Genetics, vol. 26, no. 1, pp. 51-55, 2000.

[50] D. Weil, A. El-Amraoui, S. Masmoudi et al., "Usher syndrome type I G (USH1G) is caused by mutations in the gene encoding SANS, a protein that associates with the USH1C protein, harmonin," Human Molecular Genetics, vol. 12, no. 5, pp. 463471, 2003.

[51] H. Bolz, B. Von Brederlow, A. Ramírez et al., "Mutation of $\mathrm{CDH} 23$, encoding a new member of the cadherin gene family, causes Usher syndrome type 1D," Nature Genetics, vol. 27, no. 1, pp. 108-112, 2001.

[52] E. Van Wijk, R. J. E. Pennings, H. Te Brinke et al., "Identification of 51 novel exons of the Usher syndrome type 2a (USH2A) gene that encode multiple conserved functional 
domains and that are mutated in patients with Usher syndrome type II," American Journal of Human Genetics, vol. 74, no. 4, pp. 738-744, 2004.

[53] A. Adato, S. Vreugde, T. Joensuu et al., "USH3A transcripts encode clarin-1, a four-transmembrane-domain protein with a possible role in sensory synapses," European Journal of Human Genetics, vol. 10, no. 6, pp. 339-350, 2002.

[54] I. Ebermann, J. B. Phillips, M. C. Liebau et al., "PDZD7 is a modifier of retinal disease and a contributor to digenic Usher syndrome," Journal of Clinical Investigation, vol. 120, no. 6, pp. 1812-1823, 2010.

[55] E. van Wijk, B. van der Zwaag, T. Peters et al., "The DFNB31 gene product whirlin connects to the Usher protein network in the cochlea and retina by direct association with USH2A and VLGR1," Human Molecular Genetics, vol. 15, no. 5, pp. 751765, 2006.

[56] A. El-Amraoui and C. Petit, "Usher I syndrome: unravelling the mechanisms that underlie the cohesion of the growing hair bundle in inner ear sensory cells," Journal of Cell Science, vol. 118, no. 20, pp. 4593-4603, 2005.

[57] H. Kremer, E. van Wijk, T. Märker, U. Wolfrum, and R. Roepman, "Usher syndrome: molecular links of pathogenesis, proteins and pathways," Human Molecular Genetics, vol. 15, no. 2, pp. R262-R270, 2006.

[58] J. Reiners, K. Nagel-Wolfrum, K. Jürgens, T. Märker, and U. Wolfrum, "Molecular basis of human Usher syndrome: deciphering the meshes of the Usher protein network provides insights into the pathomechanisms of the Usher disease," Experimental Eye Research, vol. 83, no. 1, pp. 97-119, 2006.

[59] B. Boëda, A. El-Amraoui, A. Bahloul et al., "Myosin VIIa, harmonin and cadherin 23, three Usher I gene products that cooperate to shape the sensory hair cell bundle," The EMBO Journal, vol. 21, no. 24, pp. 6689-6699, 2002.

[60] J. Reiners, E. van Wijk, T. Märker et al., "Scaffold protein harmonin (USH1C) provides molecular links between Usher syndrome type 1 and type 2," Human Molecular Genetics, vol. 14, no. 24, pp. 3933-3943, 2005.

[61] P. Kazmierczak, H. Sakaguchi, J. Tokita et al., "Cadherin 23 and protocadherin 15 interact to form tip-link filaments in sensory hair cells," Nature, vol. 449, no. 7158, pp. 87-91, 2007.

[62] J. McGee, R. J. Goodyear, D. R. McMillan et al., "The very large G-protein-coupled receptor VLGR1: a component of the ankle link complex required for the normal development of auditory hair bundles," Journal of Neuroscience, vol. 26, no. 24, pp. 6543-6553, 2006.

[63] A. Adato, G. Lefèvre, B. Delprat et al., "Usherin, the defective protein in Usher syndrome type IIA, is likely to be a component of interstereocilia ankle links in the inner ear sensory cells," Human Molecular Genetics, vol. 14, no. 24, pp. 3921-3932, 2005.

[64] X. Liu, I. P. Udovichenko, S. D. M. Brown, K. P. Steel, and D. S. Williams, "Myosin VIIa participates in opsin transport through the photoreceptor cilium," Journal of Neuroscience, vol. 19, no. 15, pp. 6267-6274, 1999.

[65] D. S. Williams, "Transport to the photoreceptor outer segment by myosin VIIa and kinesin II," Vision Research, vol. 42, no. 4, pp. 455-462, 2002.

[66] D. S. Papermaster, "The birth and death of photoreceptors: the Friedenwald lecture," Investigative Ophthalmology \& Visual Science, vol. 43, no. 5, pp. 1300-1309, 2002.

[67] T. Maerker, E. van Wijk, N. Overlack et al., "A novel Usher protein network at the periciliary reloading point between molecular transport machineries in vertebrate photoreceptor cells," Human Molecular Genetics, vol. 17, no. 1, pp. 71-86, 2008.

[68] R. Roepman and U. Wolfrum, "Subcellular proteomics," in Protein Networks and Complexes in Photoreceptor Cilia, E. Bertrand and M. Faupel, Eds., chapter 10, pp. 209-235, Springer, New York, NY, USA, 2007.

[69] X. Liu, O. V. Bulgakov, K. N. Darrow et al., "Usherin is required for maintenance of retinal photoreceptors and normal development of cochlear hair cells," Proceedings of the National Academy of Sciences of the United States of America, vol. 104, no. 11, pp. 4413-4418, 2007.

[70] D. Gibbs, J. Kitamoto, and D. S. Williams, "Abnormal phagocytosis by retinal pigmented epithelium that lacks myosin VIIa, the usher syndrome 1B protein," Proceedings of the National Academy of Sciences of the United States of America, vol. 100, no. 11, pp. 6481-6486, 2003.

[71] F. P. M. Cremers, W. J. Kimberling, M. Külm et al., "Development of a genotyping microarray for Usher syndrome," Journal of Medical Genetics, vol. 44, no. 2, pp. 153-160, 2007.

[72] T. Jaijo, E. Aller, G. García-García et al., "Microarraybased mutation analysis of 183 Spanish families with Usher syndrome," Investigative Ophthalmology \& Visual Science, vol. 51, no. 3, pp. 1311-1317, 2010.

[73] C. Ayuso and J. M. Millan, "Retinitis pigmentosa and allied conditions today: a paradigm of translational research," Genome Medicine, vol. 2, article 34, 2010. 


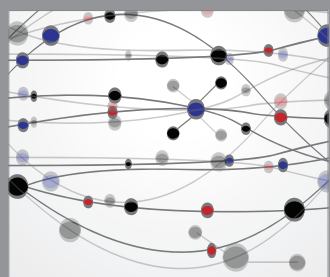

The Scientific World Journal
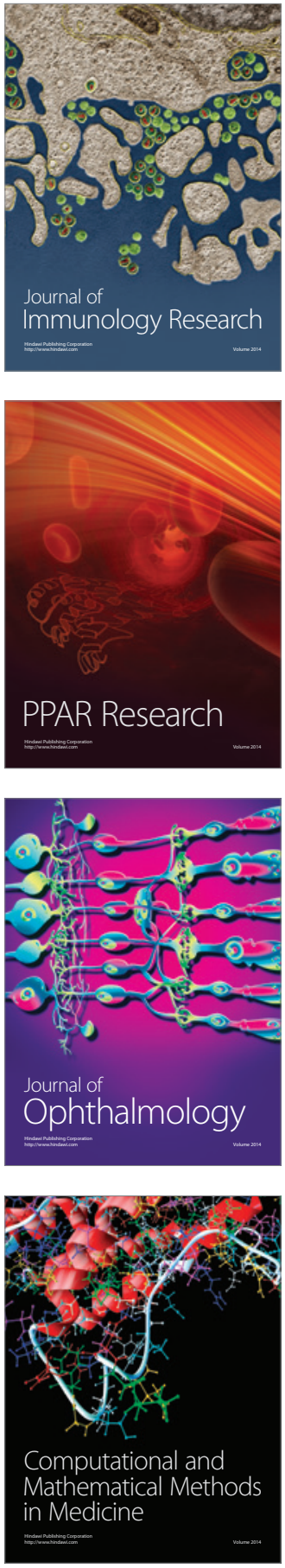

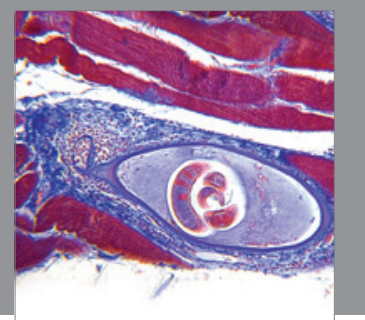

Gastroenterology

Research and Practice
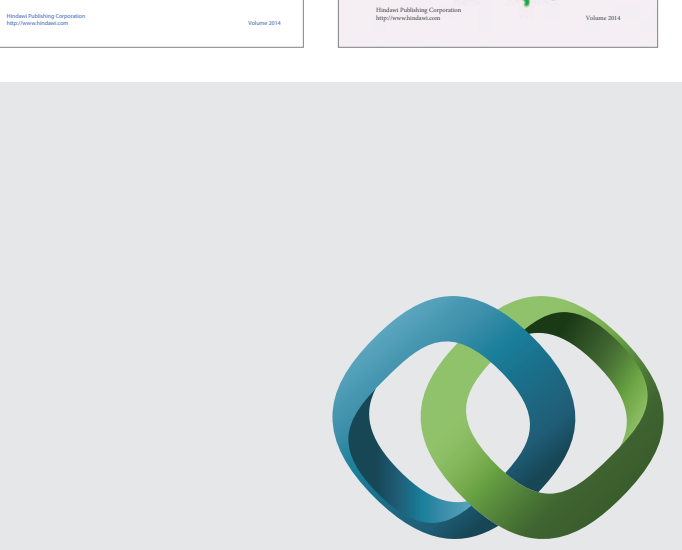

\section{Hindawi}

Submit your manuscripts at

http://www.hindawi.com
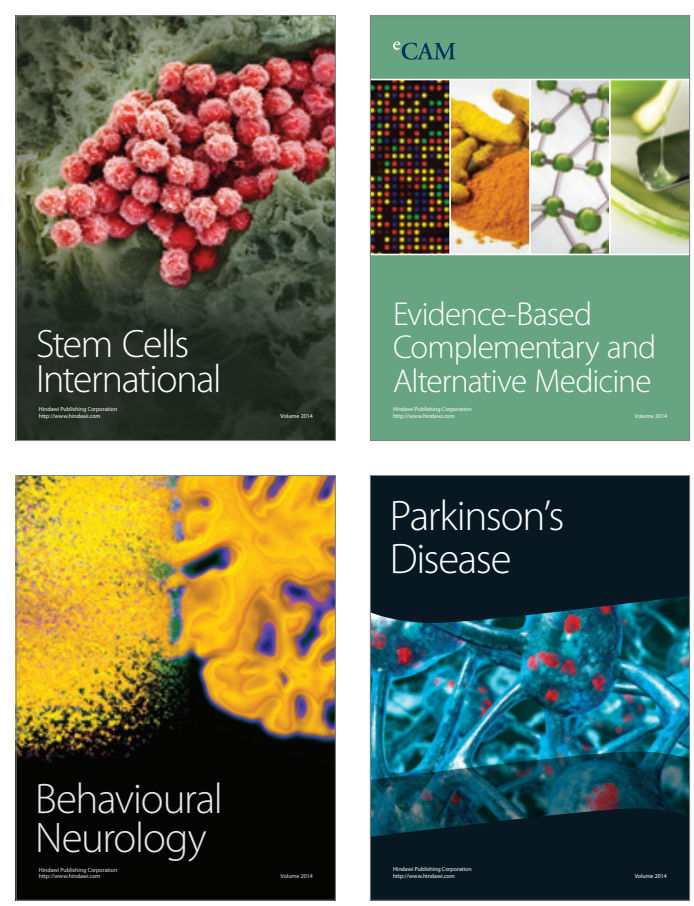

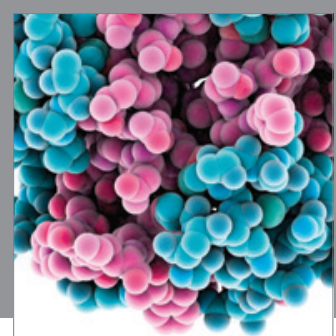

Journal of
Diabetes Research

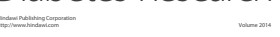

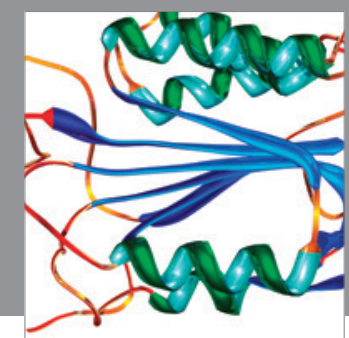

Disease Markers
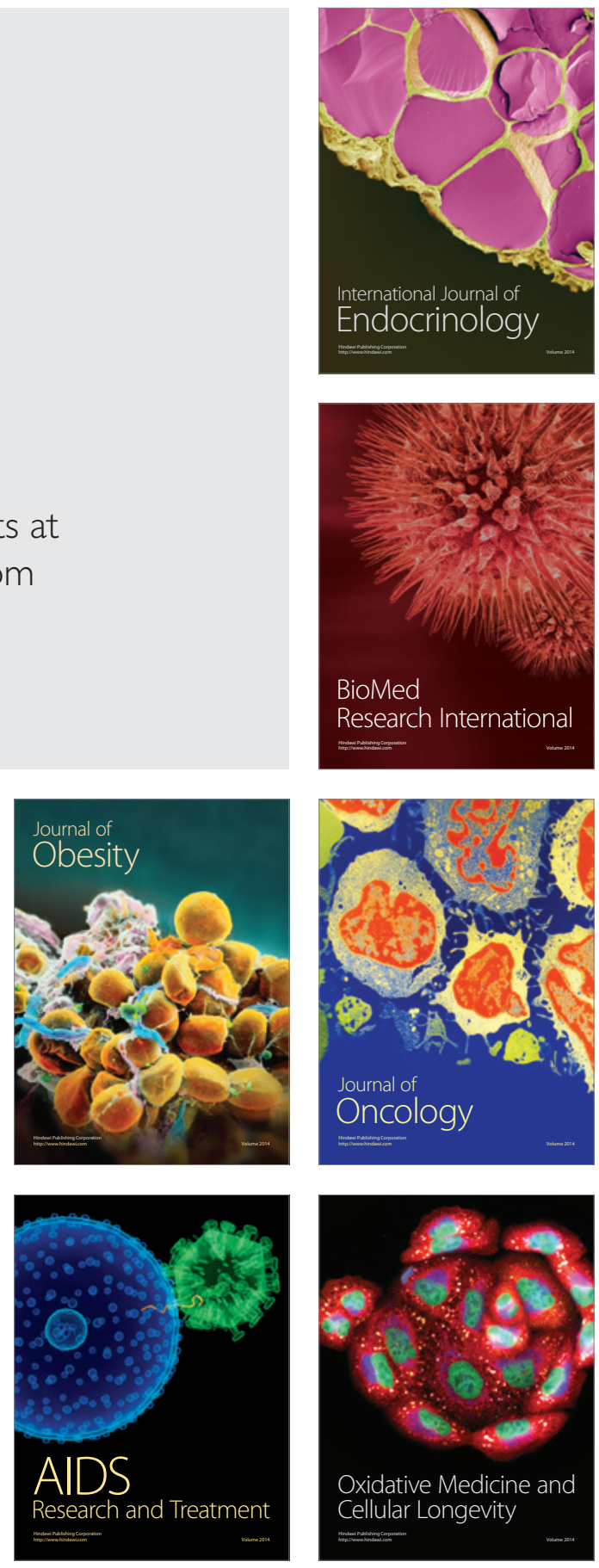